\title{
Engaging the Environment and Science Concepts Into Housekeeping Curriculum Through the Development of Disaster Prevention Cap
}

\author{
Lin Hung Tai \\ National Chi Nan University, Taichung City, Taiwan
}

\begin{abstract}
The purpose of this study is to integrate the environment, science, and housekeeping curriculum through the development of disaster prevention cap. This study tried to develop a new class to integrate science, environment, and housekeeping curriculum to help students practice their scientific and environmental knowledge into real life. There are 600 junior high school students participated in this study, 300 students with eight classes as the control group and the others as the experimental group. The control group were asked to prevent disaster by general way and the experimental group were asked to prevent disaster by using the disaster prevention cap which was designed by themselves. A test about scientific and environmental concepts was developed by the researchers in this study. All of the participants need to complete the test before and after the disaster prevention activities. From the variance analysis, the results showed that the experimental group got significantly higher scores than control group after the treatment in this study. This study successfully developed a new curriculum to engage the science and environment concepts into housekeeping curriculum, and found that students could learn the science and environment concepts well.
\end{abstract}

Keywords: disaster prevention, environmental concepts, housekeeping curriculum

\section{Introduction}

Learning motivation is one of the most important things in students' learning (Huang \& Liu, 2012). Previous studies also mentioned that motivation is one of the key points to promote students' learning and activities (Hynd, Holschuh, \& Nist, 2000; Huang \& Liu, 2012; Pintrich, 2003). It means that students will not be active without learning motivation. In 2015, the National Student Clearinghouse Research Center also provided that many high school female students lost their interest in learning science, since they could not find the relationship between science and real life (Huang, Shih, Chen, \& Liu, 2015).

In this case, we need to reflect that how could the science which junior or senior high school students learn right now be applied in their daily life? If the answer is not, why should these students need to learn? The gap among scientific knowledge, environmental knowledge, and applications are always huge. For exploring the educational question, this study tried to develop a new curriculum which involved in the science and environment concepts to practice in students' daily life. Slavin (1997) mentioned that helping students to solve ill-structured problems could improve students' concepts learning, and the problems which could be occurred in daily life and can not be expected are one kind of ill-structured problems. Based on this idea, this study

Lin Hung Tai, doctoral student, Educational Policy and Administration Department, National Chi Nan University. 
designed a new curriculum - "How to protect yourselves in earthquake" to be the main teaching subject.

In this study, we integrate the environmental, science, and housekeeping curriculum through the development of disaster prevention cap. We want to help students practice their scientific and environmental knowledge into real life. On the other hand, since the National Student Clearinghouse Research Center (2015) mentioned that a lot of female students could not find the relationship between science knowledge and real life, this study want to design a curriculum module to let students know that the knowledge will always be useful in their daily life.

Therefore, the purpose of this study is to develop a new curriculum — design a disaster prevention cap, to integrate science, environment, and housekeeping curriculum and help students practice their knowledge into real life.

\section{Research Design}

There are three parts will be introduced in the section of research design, which included in the introduction of participants and instrument, the procedure of research design, and the details of curriculum design.

\section{Participants and Instrument}

There are 600 junior high school students participated in this study $(N=600$, mean age $=13.6), 300$ students with eight classes as the control group and the others as the experimental group. All of these students are from the same junior high school which located in the central of Taiwan. They are all Grade 8 students. Besides students, there are three science teachers, one art teacher, and one housekeeping teacher involved in this study.

In this study, the "junior high school students' scientific and environmental knowledge about life" questionnaire which included in scientific and environmental concepts was developed by the researchers in this study. There are 12 items included in this questionnaire. The scales are follow the Likert's five point scale theory. The total scores are 60 points. The contents involved of science concepts (eg., What kind of materials could pretect your head most?), environmental concepts (eg., What could you do first when earthquake occurred?), and housekeeping concepts (eg., What kind of sewing methods could make your cap strong?). All of these questions are single choice. The reliability is Cronbach $\alpha=0.81$.

\section{Procedure of Research Design}

In the beginning of this study, all of the students needed to complete the "junior high school students' scientific and environmental knowledge about life" questionnaire to be the pre-test. After completing the pre-test, both the control and experiment group students were been taught the scientific and environmental concepts about earthquake in Taiwan in their science class. Then, the control group students were asked to review the matter needing attention when earthquake occurred, while the experiment group students were joined in the curriculum of this study. After teaching the knowledge of earthquake, the science teacher will teach the experimental students the notion of disaster prevention and the suitable materials to produce the disaster prevention cap. The experimental students will design their own disaster prevention cap in art class, after they complete the science class. At last, the experimental students need to complete their own cap by themselves in the housekeeping class.

The last step of this study was asking all students to complete the "junior high school students' scientific and environmental knowledge about life" questionnaire again to be as post-test data. The period of the research time is about six months, and the procedure is shown in Figure 1. 


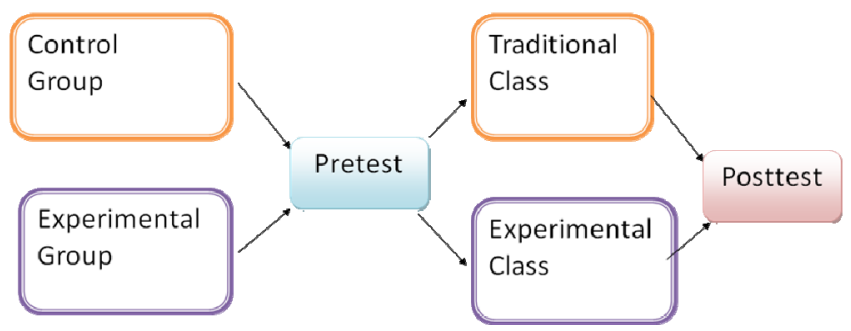

Figure 1. The procedure of research design.

\section{The Details of Curriculum Design}

In this study, the experimental students will be treated by the new curriculum which is designed by the author (see Figure 2).

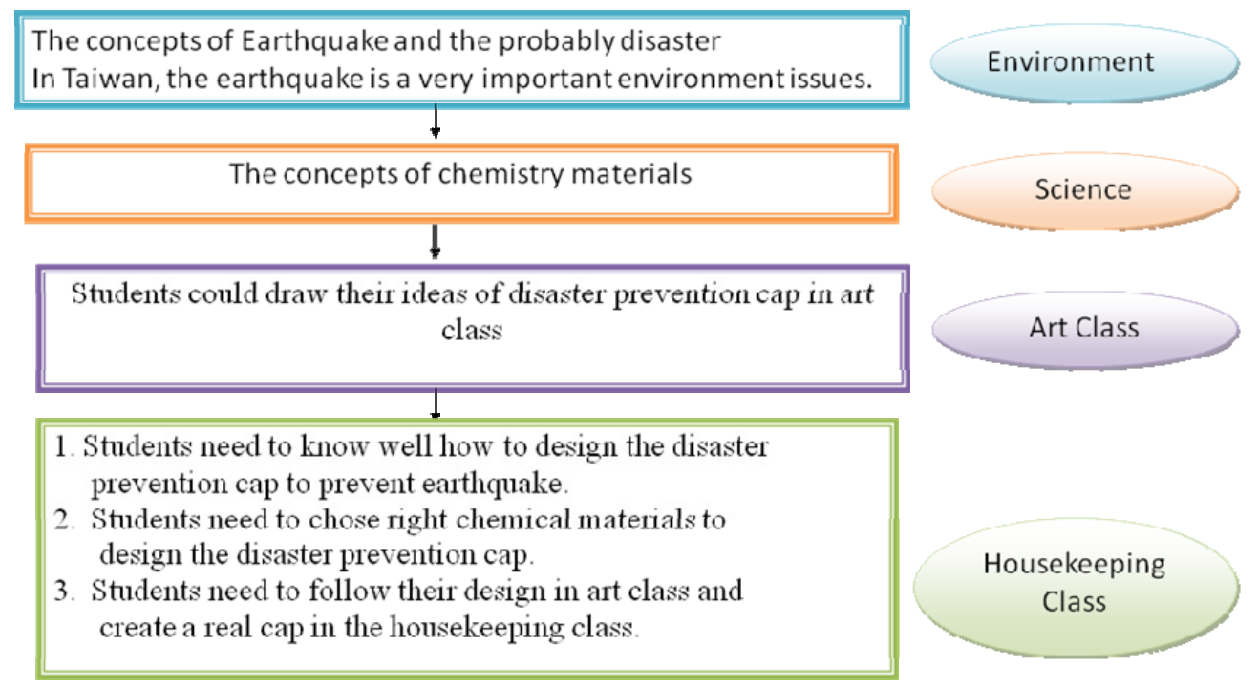

Figure 2. The details of curriculum design in this study.

In the beginning, the science teachers will teach the experiment students both the science theory of earthquake, such as plate movement theory and the chemical materials which could protect their bodies better, such as fire prevention materials.

After science class, the experimental students were asked to design their own disaster prevention cap in art class, and to produce their own disaster prevention cap by themselves in the housekeeping class (see Figure 3).

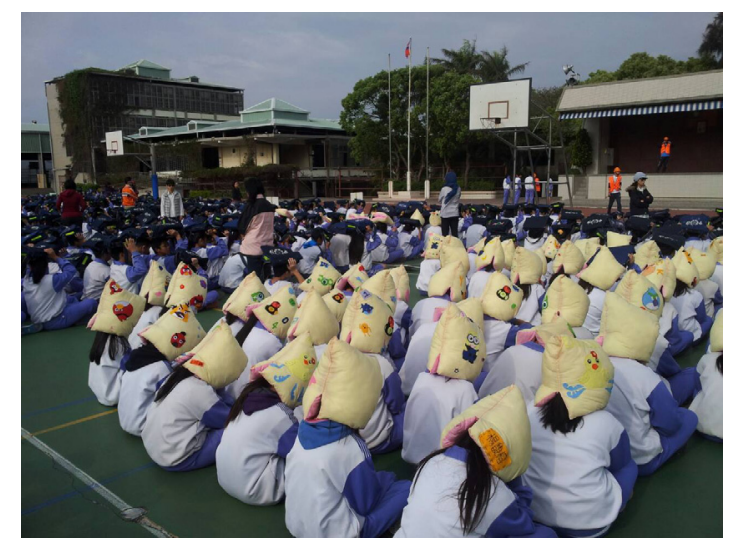

Figure 3. Students' disaster prevention cap. 


\section{Results}

This study aimed to develop a new curriculum to integrate science, environment, and housekeeping class and help students practice their knowledge in their daily life. All the students were asked to complete the "junior high school students' scientific and environmental knowledge about life" questionnaire before and after the curriculum which is designed by this study.

For clarify the effects of the treatment in this study, the data were calculated by $t$-test. Table 1 shows the two group students' average scores and standard deviation (SD), and the results of $t$-test. The results from Table 1 indicated that the two group students got similar performance in science and environment knowledge before this research. However, the experiment group students got significant higher scores than control group students after this research. It means that the curriculum which the author designed in this study could improve students' performance of science and environment knowledge.

Table 1

The Results of T-Test Between Two Groups Before and After the Treatment

\begin{tabular}{llll}
\hline Before/After treatment & Group & $\begin{array}{l}\text { Average scores } \\
(\mathrm{SD})\end{array}$ & $t$-value \\
\hline \multirow{2}{*}{ Pre-test } & Control & $47.0(7.2)$ & 0.29 \\
& Experiment & $46.1(6.9)$ & \\
\multirow{2}{*}{ Post-test } & Control & $48.0(5.9)$ & $-2.23^{*}$ \\
\hline
\end{tabular}

Note. ${ }^{*} p<0.05$.

Table 2

The Results of Paired T-Test (Pre-Test vs. Post-Test) Between Two Groups

\begin{tabular}{lll}
\hline Group & $t$-value & Sig. \\
\hline Control & -1.8 & 0.107 \\
Experiment & $-7.1^{* * *}$ & 0.000 \\
\hline
\end{tabular}

Note. ${ }^{* * *} p<0.001$.

For clarifying the improvement situation between the control and experiment groups, this study further calculate the paired $t$-test between these two groups (see Table 2).

The analysis from Table 2 shows that the control group students got the similar scores before and after this research, while the experiment group students got significant higher scores after this research than before. The results confirmed that the curriculum which is designed by this study could improve students' performances in science and environment knowledge.

The informal interview data proved that the students needed to integrate all concepts about earthquake to produce their own earthquake disaster prevention cap. To make their own cap could improve students' motivation to learn about the concepts of earthquake. For producing a suitable and applicator earthquake disaster prevention cap, they needed to know the scientific and environmental concepts of earthquake well. Some students mentioned that they tried their best to produce the cap, because they believe that the earthquake disaster prevention cap is stronger needed in real life in Taiwan.

The informal interview data demonstrate that the aim of this study - to integrate knowledge to apply in daily life, does really work in this study. 


\section{Conclusion}

One of the most important things to promote students to learn is learning motivation, while the most important reason why people need to learn is using the knowledge to solve problems in daily life. Hence, this study tried to combine the knowledge of science and environment from daily life and help to promote students' learning motivations and knowledge applications.

From the statistic analysis, the results of this study indicated that this study successfully developed a new curriculum to engage the science and environment concepts into housekeeping curriculum, and found that students could learn the science and environment concepts well.

\section{References}

Huang, C. F., \& Liu, C. J. (2012). Exploring the influences of elementary school students' learning motivation on web-based collaborative learning. US-China Education Review A, 2(6), 613-618.

Huang, C. F., Shih, C. S., Chen, G. J., \& Liu, C. J. (2015). The relationship between drawing stereotypic images and female students' science learning motivation. US-China Education Review B, 5(10), 665-672.

Hynd, C., Holschuh, J., \& Nist, S. (2000). Learning complex scientific information: Motivation theory and its relation to student perceptions. Reading \& Writing Quarterly: Overcoming Learning Difficulties, 16(1), 23-57.

National Student Clearinghouse Research Center. (2015). Reserch center news. Retrieved from http:// https://nscresearchcenter. org/

Pintrich, P. R. (2003). A motivational science perspective on the role of student motivation in learning and teaching contexts. Journal of Educational Psychology, 95(4), 667-686.

Slavin, R. E. (1997). Design competitions: A proposal for a new federal role in educational research and development. Educational Researcher, 26(1), 22-28. 